Check for updates

Cite this: RSC Adv., 2018, 8, 29662

\title{
Theoretical research on excited-state intramolecular proton coupled charge transfer modulated by molecular structure
}

\author{
Dapeng Yang, (DD *ac Guang Yang, ${ }^{\mathrm{b}}$ Min Jia, ${ }^{2}$ Xiaoyan Song, ${ }^{a}$ Qiaoli Zhang, ${ }^{a}$ \\ Tianjie Zhang ${ }^{a}$ and Haiyan Gao ${ }^{a}$
}

At the TD-B3LYP/TZVP/IEFPCM theory level, we have theoretically studied the excited-state intramolecular proton coupled charge transfer (ESIPCCT) process for both 4'-N,N-diethylamino-3-hydroxyflavone (3HFN) and 2-\{[2-(2-hydroxyphenyl)benzo[d]oxazol-6-yl]methylene\}malononitrile (diCN-HBO) molecules. Our calculated hydrogen bond lengths and angles sufficiently confirm that the intramolecular hydrogen bonds $\mathrm{O}_{1}-\mathrm{H}_{1} \cdots \mathrm{O}_{2}$ and $\mathrm{O}_{1}-\mathrm{H}_{1} \cdots \mathrm{N}_{1}$ formed at the $\mathrm{S}_{0}$ states of $3 \mathrm{HFN}$ and diCN-HBO should be significantly strengthened in the $\mathrm{S}_{1}$ state, which is further supported by the results obtained based on the analyses of infrared spectra shifts, molecular orbitals and charge density differences maps. The significant strengthening of intramolecular hydrogen bonds $\mathrm{O}_{1}-\mathrm{H}_{1} \cdots \mathrm{O}_{2}$ and $\mathrm{O}_{1}-\mathrm{H}_{1} \cdots \mathrm{N}_{1}$ upon photoexcitation should facilitate the ESIPCCT process of the two title molecules. The scanned potential energy curves and confirmed excited-state transition states for both 3HFN and diCN-HBO show that the proton can be easily transferred from $\mathrm{O}_{1}$ to $\mathrm{O}_{2}\left(\mathrm{~N}_{1}\right.$ for diCN-HBO) through the strengthened intramolecular hydrogen bonds upon photoexcitation to the $\mathrm{S}_{1}$ state.

Received 12th July 2018

Accepted 9th August 2018

DOI: $10.1039 / \mathrm{c} 8 \mathrm{ra05945d}$

rsc.li/rsc-advances excitation, the redistribution of electronic charge makes the proton donor more acidic and the acceptor more basic. Thermodynamically, the enhancement in the basicity/acidity factor, which is several orders of magnitude, makes ESIPT energetically favorable and provides the strong driving force for its occurrence, which explains why the same reaction does not occur in the ground state.

The redistribution of electron density does not only provide the driving force of ESIPT. The charge relocation can be reinforced by the integration of weak intermolecular interactions (such as solute/solvent dipole-dipole interactions), which dramatically influence both reaction kinetics and thermodynamics. Electronically excited to the Franck-Condon state, a molecule with an enhanced distribution of electronic charge and thus a large change of dipole moment strongly polarizes the surrounding medium. This leads to a dielectrically stabilized charge-transfer $\left(\mathrm{CT}^{*}\right)$ excited state. The reaction leading to this state can be referred to as the excited state intramolecular charge transfer (ESICT) state. Such stabilization can also occur from the product side of ESIPT if the reaction generates a substantial charge transfer character. In a word, upon electronic excitation, the redistribution of electronic charge from electronic charge donor to accepter obviously enhances the dipole moment of the molecule, which makes the proton donor more acidic and the acceptor more basic and finally facilitates the excited-state proton transfer.

The prerequisite of ESIPT lies in the formation of an intramolecular hydrogen bond. Recent advances have shown that 
hydrogen bonds play an important role in the excited-state behavior of molecular dyes. For instance, several theoretical approaches have explored the site-specific intermolecular excited state hydrogen bonding (H-bonding) property and found interesting correlations for fluorescence quenching, the dynamics of intermolecular charge transfer, and the spectral shifts versus the intermolecular H-bonding strength in the excited state..$^{7,25-28}$ Thus, one would expect that the H-bonding properties, such as strength, distance and orientation, should affect ESIPT, ESICT, and consequently the ESIPT-ESICT coupled reaction.

The proton is a positively charged particle and its transfer leads to a new redistribution of electron density in the molecule in solution. When the ESIPT reaction is observed in condensed dielectric media, the dielectric polarization of the environment can have a substantial impact on photophysical events, stabilizing the charge-separated states. Therefore, the ESIPT process can be coupled with ESICT reaction both kinetically and energetically. ${ }^{29-31}$ This coupling depends strongly on the molecular structure. There are systems in which the interplay between ESICT and ESIPT is apparent, rendering drastically different photophysical phenomena such as dual emissions simultaneously associated with both ESIPT and ESICT. For example, as in the case of $\mathbf{3} \mathbf{H F N}^{\mathbf{2 2 , 2 4}}$ (shown in Scheme 1), when ESICT takes place upon Franck-Condon excitation, i.e., $\mathrm{N}-\mathrm{N}^{*}(\mathrm{~N}$ : normal ground populated state, $\mathrm{N}^{*}$ : electronically excited state), $\mathrm{N}^{*}$ may thus have large charge separation. The subsequent $\mathrm{N}^{*}-\mathrm{T}^{*}$ ESIPT ( $\mathrm{T}^{*}$ stands for excited tautomer), leading to strong redistribution of the electronic density, may be subject to drastic change of the dipole moment. For the other possibility, as in the case of diCN-HBO $^{23,24}$ (shown in Scheme 1), the ESICT state is not formed upon excitation, whereas ESIPT is accompanied by significant charge separation. Thus, the $\left(\mathrm{T}^{*}\right)$ form attains the property of the ESICT state and then relaxes to the $(\mathrm{N})$ state via the $(\mathrm{T})$ state, closing a reaction cycle.

The 3HFN molecule is strategically designed so that it undergoes ESICT prior to the ESIPT reaction..$^{22,24}$ As depicted in Scheme 1 , the electron donor ( $D_{e}$, the dialkyamino group) and proton donor $\left(\mathrm{D}_{\mathrm{p}}, \mathrm{O}_{1}-\mathrm{H}_{1}\right)$ occupy different positions but the same group serves as both proton acceptor and electron acceptor $\left(\mathrm{A}_{\mathrm{e}, \mathrm{p}}, \mathrm{O}_{2}\right)$. Upon photoexcitation, ultrafast ESICT takes place, generating the $\mathrm{CT}^{*}$ state on time scale (a few hundred femtoseconds). Subsequently, the solvent relaxation process from $\mathrm{CT}^{*}$ to $\mathrm{CT}_{\mathrm{eq}}^{*}$ (subscript eq: equilibrium) and ESIPT occur competitively. After reaching the solvent equilibrium, proton transfer reaction from $\mathrm{CT}_{\mathrm{eq}}^{*}$ to $\mathrm{PCT}^{*}$ takes place. The diCN-HBO molecule is strategically designed so that it undergoes ESIPT prior to the ESICT reaction. ${ }^{\mathbf{2 3 2}}$ As depicted in Scheme 1, the proton acceptor $\left(A_{p}, N_{1}\right)$ and electron acceptor $\left(A_{e}\right.$, the di-cyano group) are at different positions but the proton donor and electron donor are the same $\left(\mathrm{D}_{\mathrm{e}, \mathrm{p}}, \mathrm{O}_{1}-\mathrm{H}_{1}\right)$. The $\mathrm{D}_{\mathrm{e}, \mathrm{p}}$ group of diCN-HBO molecule is not a strong electron donating group in the excited state until it forms an anion via transferring a proton $\left(\mathrm{H}^{+}\right)$to the proton acceptor $\mathrm{A}_{\mathrm{p}}$. Once the proton is transferred, the resulting oxide anion $-\mathrm{O}_{1}{ }^{-}$becomes a powerful electron donating group. Since $\mathrm{D}_{\mathrm{e}, \mathrm{p}}$ is $\pi$-conjugated with the electron acceptor $\mathrm{A}_{\mathrm{e}}$, a strong coupling matrix between $\mathrm{D}_{\mathrm{e}}{ }^{-}$and $\mathrm{A}_{\mathrm{e}}$ is then expected, which should execute charge transfer toward the electron accepting cyano-group via $\pi$-conjugation. However, the overall perspective mechanism of the ESIPCCT process for the two molecules are not fully understood, especially in the computational way. Therefore, in this work, we are motivated to elucidate the overall perspective mechanism of the ESIPCCT process for the two molecules 3HFN and diCN-HBO in a computational way by optimizing geometrical structures, analyzing molecular orbitals and charge density difference maps as well as the infrared vibrational spectra, especially the potential energy curves.

In this work, we aim to present a detailed and overall perspective of the ESIPCCT process for both 3HFN and diCNHBO molecules at the TD-B3LYP/TZVP/IEFPCM theory level since time dependent density functional theory (TDDFT) method has been demonstrated to be a reliable tool to investigate the excited state dynamics ${ }^{7,25-28,32-36}$ and provide a clear mechanism for previous experiment. The work is organized as follows: Section 2 introduces the computational methods adopted in this work; Section 3 presents the results and discussions, including functional test, optimized geometrical structures, molecular orbitals and charge density difference maps, infrared vibrational spectra analyses as well as potential energy curves and transfer mechanism; Section 4 gives the conclusion of this research work.

\section{Computational methods}

Using density functional theory (DFT) and time dependent density functional theory (TDDFT) methods with Becke's threeparameter hybrid exchange function with the Lee-Yang-Parr

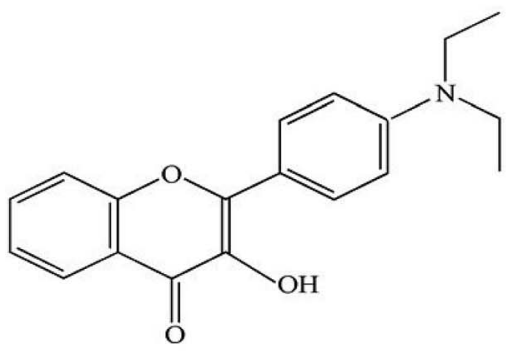

3HFN<smiles>N#CC(C#N)=Cc1ccc2nc(-c3ccccc3O)oc2c1</smiles>

diCN-HBO

Scheme 1 Geometrical structures of 3HFN and diCN-HBO. 
gradient-corrected correlation functional (B3LYP) ${ }^{37-42}$ as well as the TZVP basis set, we have theoretically studied the excitedstate overall perspective of proton coupled charge transfer process modulated by molecular structure within 3HFN and diCN-HBO systems by Gaussian 09 program. ${ }^{43}$ Since previous experimental works were carried out in dichloromethane and chloroform solvents for $\mathbf{3 H F N}$ and diCN-HBO respectively, ${ }^{22-24}$ we took these two solvents into consideration in all calculations via Polarizable Continuum Model (PCM) using the integral equation formalism variant (IEF-PCM) $)^{\mathbf{4 4 - 4 6}}$ to be consistent with former experiments. ${ }^{22-24}$ For the ground-state part, all the corresponding structures (see Fig. 1 and 2) have been optimized without constraint using DFT methodology with vibrational frequencies analyses to ensure that all these configurations correspond to the local minima on the $S_{0}$ potential energy surface (PES). The calculations about vertical excitation process were carried out from the $\mathrm{S}_{0}$-state optimized structures using TDDFT method with six low-lying absorbing transitions.

Furthermore, all the $\mathrm{S}_{1}$-state calculations were also based on the $\mathrm{S}_{0}$-state optimized structures with vibrational frequencies analyses. Even though the process for scanning potential energy curves of proton transfer is very time-consuming, especially for the excited state, we have theoretically scanned the $\mathrm{S}_{0^{-}}$and $\mathrm{S}_{1^{-}}$state potential energy curves to provide the corresponding dynamical overall perspectives of proton coupled charge transfer qualitatively and quantitatively. All the stationary points along the proton transfer coordinate were scanned by constraining optimizations and frequency analyses (no imaginary frequency) to obtain the thermodynamic corrections in the corresponding electronic state. The excited-state transition

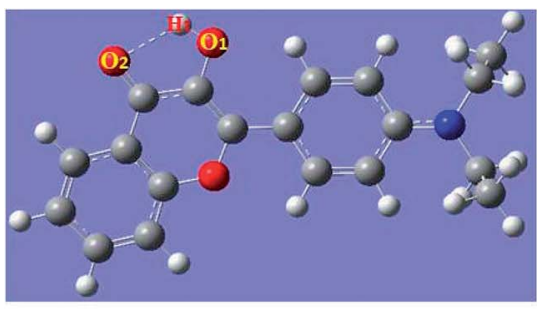

So

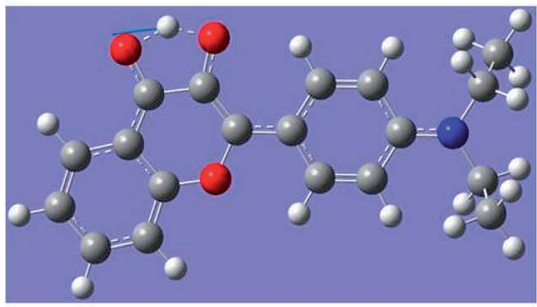

S1-TS

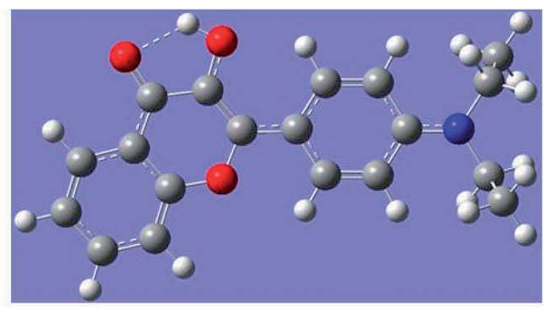

S1

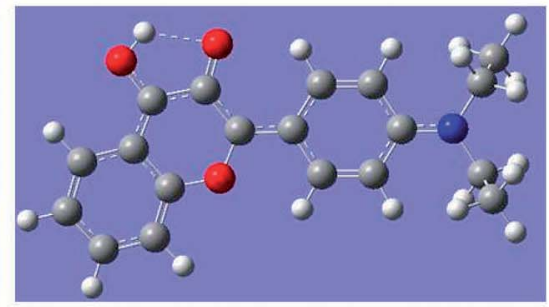

S1-PT

Fig. 1 Optimized geometrical structures of $3 \mathrm{HFN}$ in dichloromethane at ground state $\mathrm{S}_{0}$, first singlet excited state $\mathrm{S}_{1}$, transition state $\mathrm{S}_{1}$-TS and after proton transfer $\mathrm{S}_{1}-\mathrm{PT}$ at (TD)B3LYP/TZVP/IEFPCM theory level.

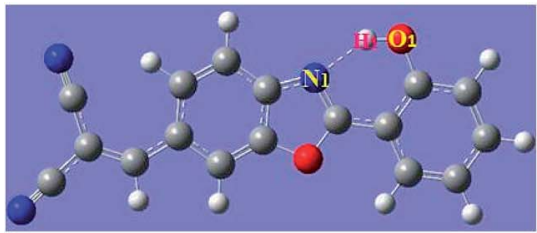

So

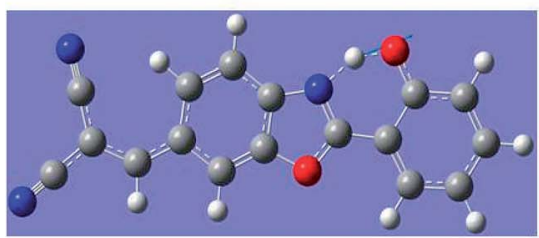

S1-TS

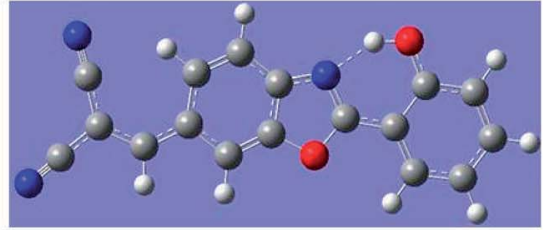

S1

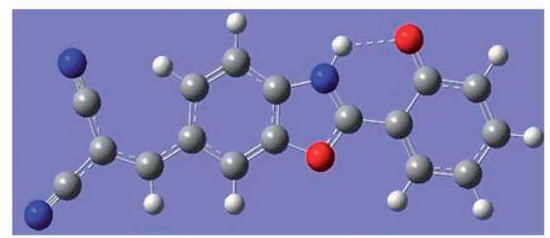

S1-PT

Fig. 2 Optimized geometrical structures of diCN-HBO in chloroform at ground state $\mathrm{S}_{0}$, first singlet excited state $\mathrm{S}_{1}$, transition state $\mathrm{S}_{1}-\mathrm{TS}$ and after proton transfer $\mathrm{S}_{1}$-PT at (TD)B3LYP/TZVP/IEFPCM theory level. 
state was confirmed based on the stationary point with the highest potential energy in the excited-state potential energy curve. The transition state should have only one imaginary frequency whose vibrational mode points to the proton transfer product. The optimization and frequency analysis of the transition state are carried out with the Gaussian 16 program. ${ }^{47}$

\section{Results and discussions}

\subsection{Functional test}

Based on experimental absorption spectra of 3HFN in dichloromethane and diCN-HBO in chloroform, we have carried out the functional test with TZVP basis set on the TD/TZVP/IEFPCM theory level and the calculated results are listed in Table 1. From Table 1 we can find that the Becke's three-parameter hybrid exchange function with the Lee-Yang-Parr gradient-corrected correlation functional B3LYP should be more suitable for describing the photoexcitation of both 3HFN in dichloromethane and diCN-HBO in chloroform. Therefore, all the calculations of the paper are at the (TD)B3LYP/TZVP/IEFPCM theory level.

\subsection{Optimized geometrical structures}

The geometrical structures of both 3HFN in dichloromethane and diCN-HBO in chloroform have been optimized at the (TD) B3LYP/TZVP/IEFPCM theory level. For convenience, we named the intramolecular hydrogen bonds within 3HFN and diCNHBO as $\mathrm{O}_{1}-\mathrm{H}_{1} \cdots \mathrm{O}_{2}$ and $\mathrm{O}_{1}-\mathrm{H}_{1} \cdots \mathrm{N}_{1}$ respectively. The optimized ground-state $\left(\mathrm{S}_{0}\right)$ and first singlet excited-state $\left(\mathrm{S}_{1}\right)$ geometrical structures of 3HFN in dichloromethane and diCN-HBO in chloroform are provided in Fig. 1 and 2 respectively and the important hydrogen bond parameters are listed in Table 2 .

Table 1 Electronic excitation energy $(\mathrm{nm})$, corresponding oscillator strengths (in parenthesis) and the corresponding compositions of the $\mathrm{S}_{0}-\mathrm{S}_{1}$ electronic transition for the 3HFN (in dichloromethane) and diCN-HBO (in chloroform) chemosensor based on the TZVP basis set and IEFPCM combined with different functionals

\begin{tabular}{lllll}
\hline & B3LYP & CAM-B3LYP & WB97XD & Exp. \\
\hline \multirow{2}{*}{ 3HFN } & $428(0.806)$ & $366(1.05)$ & $358(1.07)$ & 410 \\
& $\mathrm{H} \rightarrow \mathrm{L}(99.1 \%)$ & $\mathrm{H} \rightarrow \mathrm{L}(91.1 \%)$ & $\mathrm{H} \rightarrow \mathrm{L}(87.1 \%)$ & \\
diCN-HBO & $417(0.777)$ & $354(1.48)$ & $348(1.52)$ & 380 \\
& $\mathrm{H} \rightarrow \mathrm{L}(98.7 \%)$ & $\mathrm{H} \rightarrow \mathrm{L}(82.8 \%)$ & $\mathrm{H} \rightarrow \mathrm{L}(78.9 \%)$ &
\end{tabular}

Table 2 The calculated primary bond lengths $(\AA)$ and angles $\left(^{\circ}\right)$ of 3HFN (in dichloromethane) and diCN-HBO (in chloroform) in the $\mathrm{S}_{0}$, $\mathrm{S}_{1}, \mathrm{~S}_{1}-\mathrm{TS}$ and $\mathrm{S}_{1}-\mathrm{PT}$ states at (TD)B3LYP/TZVP/IEFPCM theory level

\begin{tabular}{|c|c|c|c|c|c|c|}
\hline & \multicolumn{3}{|l|}{ 3HFN } & \multicolumn{3}{|c|}{ diCN-HBO } \\
\hline & $\mathrm{O}_{1}-\mathrm{H}_{1}$ & $\mathrm{H}_{1} \cdots \mathrm{O}_{2}$ & $\begin{array}{l}\delta \\
\left(\mathrm{O}_{1}-\mathrm{H}_{1} \cdots \mathrm{O}_{2}\right)\end{array}$ & $\mathrm{O}_{1}-\mathrm{H}_{1}$ & $\mathrm{H}_{1} \cdots \mathrm{N}_{1}$ & $\begin{array}{l}\delta \\
\left(\mathrm{O}_{1}-\mathrm{H}_{1} \cdots \mathrm{N}_{1}\right)\end{array}$ \\
\hline $\mathrm{S}_{0}$ & 0.98 & 2.00 & 119.19 & 0.99 & 1.80 & 145.22 \\
\hline $\mathrm{S}_{1}$ & 0.99 & 1.85 & 124.71 & 1.02 & 1.65 & 147.85 \\
\hline $\mathrm{S}_{1}-\mathrm{TS}$ & 1.24 & 1.25 & 139.42 & 1.18 & 1.32 & 150.91 \\
\hline $\mathrm{S}_{1}-\mathrm{PT}$ & 1.97 & 0.98 & 119.42 & 1.94 & 1.02 & 124.97 \\
\hline
\end{tabular}

From Table 2, it can be found that the bond lengths of intramolecular hydrogen bonds $\mathrm{O}_{1}-\mathrm{H}_{1} \cdots \mathrm{O}_{2}$ in 3HFN and $\mathrm{O}_{1}-\mathrm{H}_{1} \cdots \mathrm{N}_{1}$ in diCN-HBO are both decreased from ground state $\mathrm{S}_{0}$ to first singlet excited state $S_{1}$. At the same time, the bond angles of the two intramolecular hydrogen bonds are both increased from ground state $S_{0}$ to first singlet excited state $S_{1}$.

For 3HFN in dichloromethane, the hydrogen bond length is decreased from $2.00 \AA$ in ground state $S_{0}$ to $1.85 \AA$ in first singlet excited state $S_{1}$ and the hydrogen bond angle is increased from $119.19^{\circ}$ in ground state $S_{0}$ to $124.71^{\circ}$ in first singlet excited state $S_{1}$. For diCN-HBO in chloroform, the hydrogen bond length is decreased from $1.80 \AA$ in ground state $S_{0}$ to $1.65 \AA$ in first singlet excited state $S_{1}$ and the hydrogen bond angle is increased from $145.22^{\circ}$ in ground state $S_{0}$ to $147.85^{\circ}$ in first singlet excited state $S_{1}$. Both the decreases of the hydrogen bond lengths and the increases of the hydrogen bond angles indicate that the intramolecular hydrogen bonds formed in the ground state $\mathrm{S}_{0}$ of both 3HFN and diCN-HBO systems should be significantly strengthened upon photoexcitation to the first singlet excited state $\mathrm{S}_{1}$, which should result in the excited-state proton transfer from atom $\mathrm{O}_{1}$ to atom $\mathrm{O}_{2}\left(\mathrm{~N}_{1}\right)$ for 3HFN (diCN-HBO).

\subsection{Molecular orbitals and charge density difference maps}

To visually illustrate the changes of charge distribution upon photoexcitation, the molecular orbitals responsible for the electronic transition of $\mathrm{S}_{0}-\mathrm{S}_{1}$ of $3 \mathbf{H F N}$ and diCN-HBO, namely the lowest unoccupied molecular orbital (LUMO) and the highest occupied molecular orbital (HOMO) as shown in Table 1, are provided in Fig. 3 and 4 respectively. From Fig. 3, it can be found that the charge density localized on atom $\mathrm{O}_{1}$ in HOMO of 3HFN is totally disappeared in LUMO whereas that localized on atom $\mathrm{O}_{2}$ of $3 \mathbf{H F N}$ is greatly increased from HOMO to LUMO. The charge density difference map (CCDM) of 3HFN shows the same results as that of the molecular orbitals from HOMO to LUMO. The results obtained from molecular orbitals and charge density difference map analyses indicate that due to the intramolecular charge transfer from $\mathrm{O}_{1}$ and the dialkyamino group to $\mathrm{O}_{2}$, the intramolecular hydrogen bond $\mathrm{O}_{1}-\mathrm{H}_{1} \cdots \mathrm{O}_{2}$ formed in the ground state $\mathrm{S}_{0}$ of $3 \mathbf{H F N}$ should be significantly strengthened upon photoexcitation to the first singlet excited state $S_{1}$, which should result in the excitedstate intramolecular proton transfer from atom $\mathrm{O}_{1}$ to atom $\mathrm{O}_{2}$ of $3 \mathrm{HFN}$.

For diCN-HBO, we can find from Fig. 4 that the charge densities formerly localized on both atoms $\mathrm{O}_{1}$ and $\mathrm{N}_{1}$ are almost completely disappeared from HOMO to LUMO. And the charge density difference map (CCDM) of diCN-HBO shows the same results. The charge density difference map of $\mathrm{S}_{1}$-PT-state diCNHBO (CCDM*) shows that after excited-state proton transfer of $\mathrm{H}_{1}$ from $\mathrm{O}_{1}$ to $\mathrm{N}_{1}$, the charge density formerly localized on $\mathrm{O}_{1}$ is greatly decreased and intramolecular charge transfer takes place from $\mathrm{O}_{1}$ to the di-cyano group. That is to say, the excitedstate intramolecular proton transfer of $\mathrm{H}_{1}$ from $\mathrm{O}_{1}$ to $\mathrm{N}_{1}$ in diCN-HBO results in the intramolecular charge transfer from $\mathrm{O}_{1}$ to the di-cyano group. 

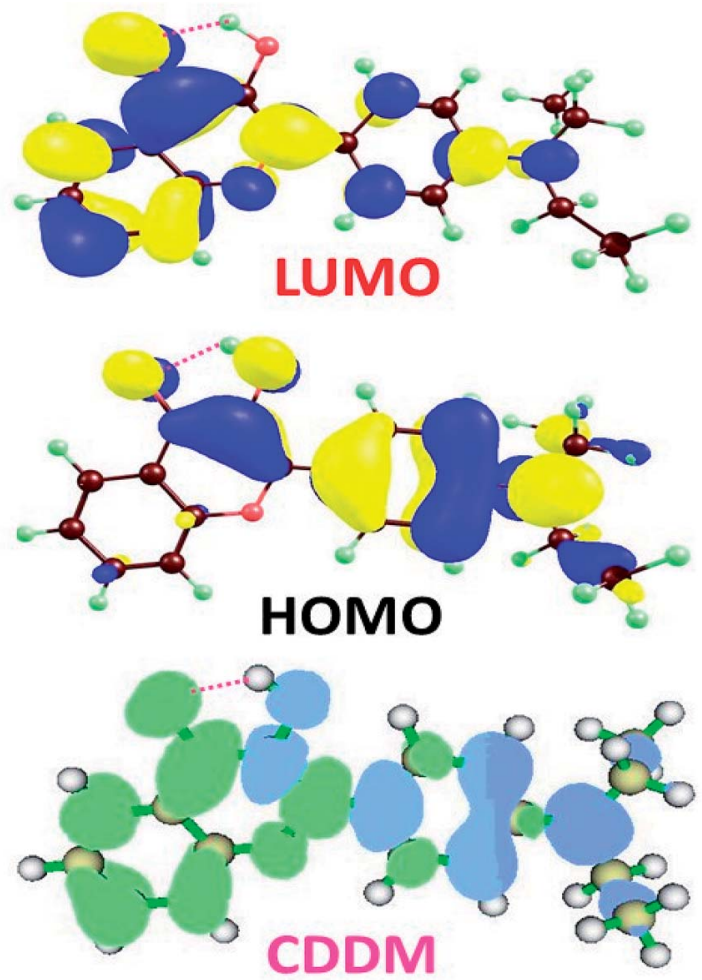

Fig. 3 Lowest unoccupied molecular orbital (LUMO), highest occupied molecular orbital (HOMO) and charge density difference map (CDDM) of 3HFN in dichloromethane at TD-B3LYP/TZVP/IEFPCM theory level. The green and blue regions in CDDM represent increase and decrease of charge density upon photoexcitation respectively.

\subsection{Infrared vibrational spectra analyses}

We all know that detecting the infrared (IR) vibrational spectral shift is an effective way to explore the changes of hydrogen bonds upon photoexcitation and it has been demonstrated that the changes of hydrogen bonding can be monitored by the

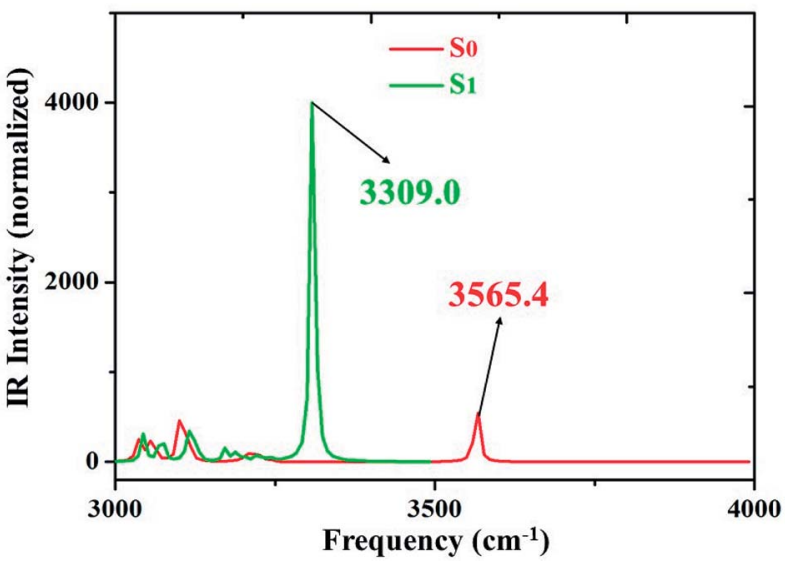

Fig. 5 IR spectra of $3 \mathrm{HFN}$ in dichloromethane at the spectral region of $\mathrm{O}_{1}-\mathrm{H}_{1}$ stretching band in both $\mathrm{S}_{0}$ and $\mathrm{S}_{1}$ states at (TD)B3LYP/TZVP/ IEFPCM theory level.

infrared spectra of some characteristic vibrational modes involved in the hydrogen bond formation. ${ }^{7,25-27}$ Therefore, the vibrational spectra involved in intramolecular hydrogen bonding moiety of $\mathbf{3 H F N}$ and $\mathbf{d i C N}-\mathbf{H B O}$ in the conjunct vibrational O-H stretching modes have been displayed in Fig. 5 and 6, respectively. From Fig. 5, it should be noticed that our calculated $\mathrm{O}_{1}-\mathrm{H}_{1}$ stretching vibrational frequency of $3 \mathbf{H F N}$ is redshifted from $3565.4 \mathrm{~cm}^{-1}$ in $\mathrm{S}_{0}$ state to $3309.0 \mathrm{~cm}^{-1}$ in $\mathrm{S}_{1}$ state. That is to say, the $256.4 \mathrm{~cm}^{-1}$ redshift is arisen from the photoexcitation. Similarly, the $\mathrm{O}_{1}-\mathrm{H}_{1}$ stretching vibrational frequency of diCN-HBO is redshifted from $3350.4 \mathrm{~cm}^{-1}$ in $\mathrm{S}_{0}$ state to $2733.4 \mathrm{~cm}^{-1}$ in $\mathrm{S}_{1}$ state and the $617 \mathrm{~cm}^{-1}$ redshift is also arisen from the photoexcitation. Han et al. have concluded that redshift of the infrared vibrational spectra of $\mathrm{O}-\mathrm{H}$ upon photoexcitation should be resulted from the strengthening of hydrogen bond with $\mathrm{O}-\mathrm{H}$ as hydrogen donor. ${ }^{7,25-27}$ Thus, we once again confirmed that the intramolecular hydrogen bonds formed in the ground state $S_{0}$ of both 3 HFN and diCN-HBO

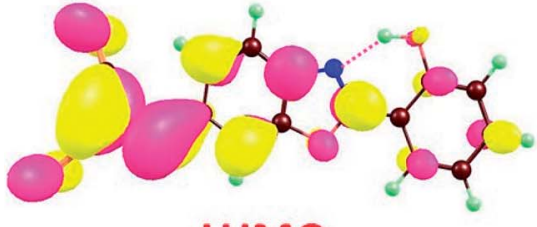

LUMO

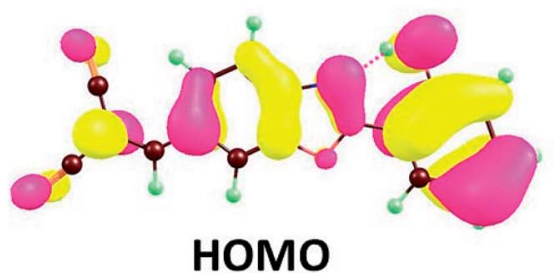

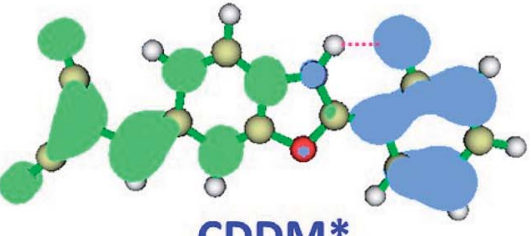

CDDM*

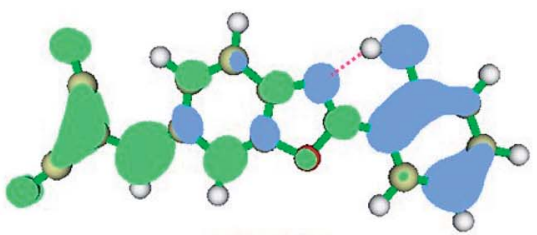

CDDM

Fig. 4 Lowest unoccupied molecular orbital (LUMO), highest occupied molecular orbital (HOMO) and charge density difference map (CDDM) of diCN-HBO in chloroform at TD-B3LYP/TZVP/IEFPCM theory level. CDDM* is for diCN-HBO after proton transfer. The green and blue regions in CDDM represent increase and decrease of charge density upon photoexcitation respectively. 


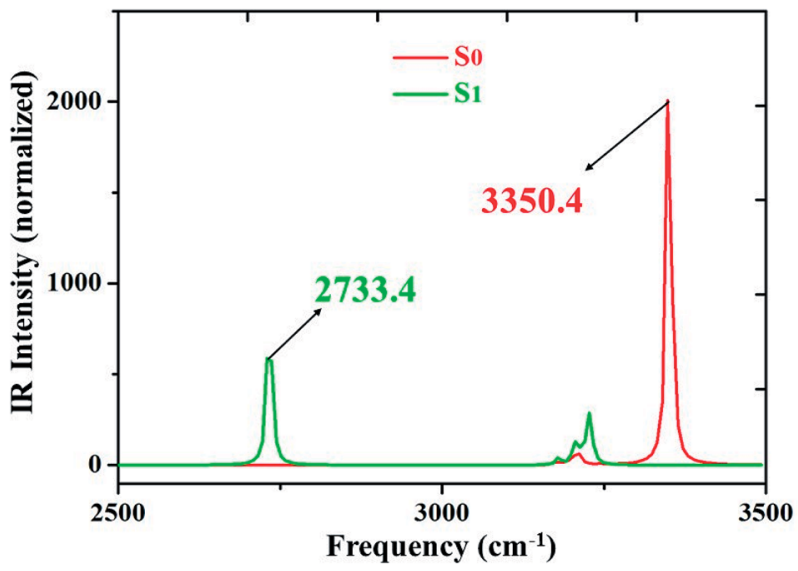

Fig. 6 IR spectra of diCN-HBO in chloroform at the spectral region of $\mathrm{O}_{1}-\mathrm{H}_{1}$ stretching band in both $\mathrm{S}_{0}$ and $\mathrm{S}_{1}$ states at (TD)B3LYP/TZVP/ IEFPCM theory level.

systems should be significantly strengthened upon photoexcitation to the first singlet excited state $\mathrm{S}_{1}$, which are consistent with the results obtained by both geometrical structure analyses and molecular orbital as well as charge density difference analyses.

\subsection{Potential energy curves and transfer mechanism}

To further reveal the detailed ESIPCCT mechanism, we have constructed the potential energy curves in both $\mathrm{S}_{0}$ and $\mathrm{S}_{1}$ states with fixing $\mathrm{H}_{1}-\mathrm{O}_{2}$ of $3 \mathrm{HFN}\left(\mathrm{H}_{1}-\mathrm{N}_{1}\right.$ for diCN-HBO) bond lengths at a series of certain values in step of $-0.05 \AA$. For 3 HFN system, the $\mathrm{H}_{1}-\mathrm{O}_{2}$ bond lengths have been fixed from $2.002 \AA$ to $1.002 \AA$ in step of $-0.05 \AA$ to scan the ground state potential energy curve, as shown in Fig. 7(a). From Fig. 7(a), we can find that the potential energy is gradually increased as the distance between atoms $\mathrm{H}_{1}$ and $\mathrm{O}_{2}$ decreases from $2.002 \AA$ to $1.152 \AA$, with a high energy barrier $12.93 \mathrm{kcal} \mathrm{mol}^{-1}$. Therefore, the proton transfer cannot happen in the ground state of $\mathbf{3 H F N}$ due to the rather high potential energy barrier. Furthermore, to scan the $\mathrm{S}_{1}$-state potential energy curve, the $\mathrm{H}_{1}-\mathrm{O}_{2}$ bond lengths have been fixed from $1.851 \AA$ to $0.951 \AA$ in step of $-0.05 \AA$. Quite different from the situation in ground state, there only exist a rather small potential barrier (around $5.05 \mathrm{kcal} \mathrm{mol}^{-1}$ ) separating the $\mathrm{S}_{1}$-state $3 \mathbf{H F N}$ and the $\mathrm{S}_{1}$-PT-state $\mathbf{3 H F N}$ (shown in Fig. $1, \mathrm{~S}_{1}-\mathrm{PT}$ ) configurations, as shown in Fig. 7(b). Furthermore, the transition-state geometrical structure (shown in Fig. 1, $\mathrm{S}_{1}$-TS) corresponding to the point with the highest potential energy in Fig. 7(b) has been confirmed to only have one imaginary frequency that points to the direction of proton transfer. More important, the energy of the $\mathrm{S}_{1}$-PT-state $\mathbf{3 H F N}$ configuration is lower than that of the $\mathrm{S}_{1}$-state $3 \mathbf{H F N}$ by $2.15 \mathrm{kcal} \mathrm{mol}^{-1}$. Thus, the intramolecular proton transfer from atom $\mathrm{O}_{1}$ to atom $\mathrm{O}_{2}$ of 3HFN can be easily realized in the first singlet excited state. After the formation of $\mathrm{S}_{1}$-PT-state $3 \mathrm{HFN}$, the radiation fluorescent process occurs with emission peak $585.59 \mathrm{~nm}$ (experimental value located at about $570 \mathrm{~nm}$ (ref. 22)) back to ground state, which is redshifted by more than $100 \mathrm{~nm}$ from that
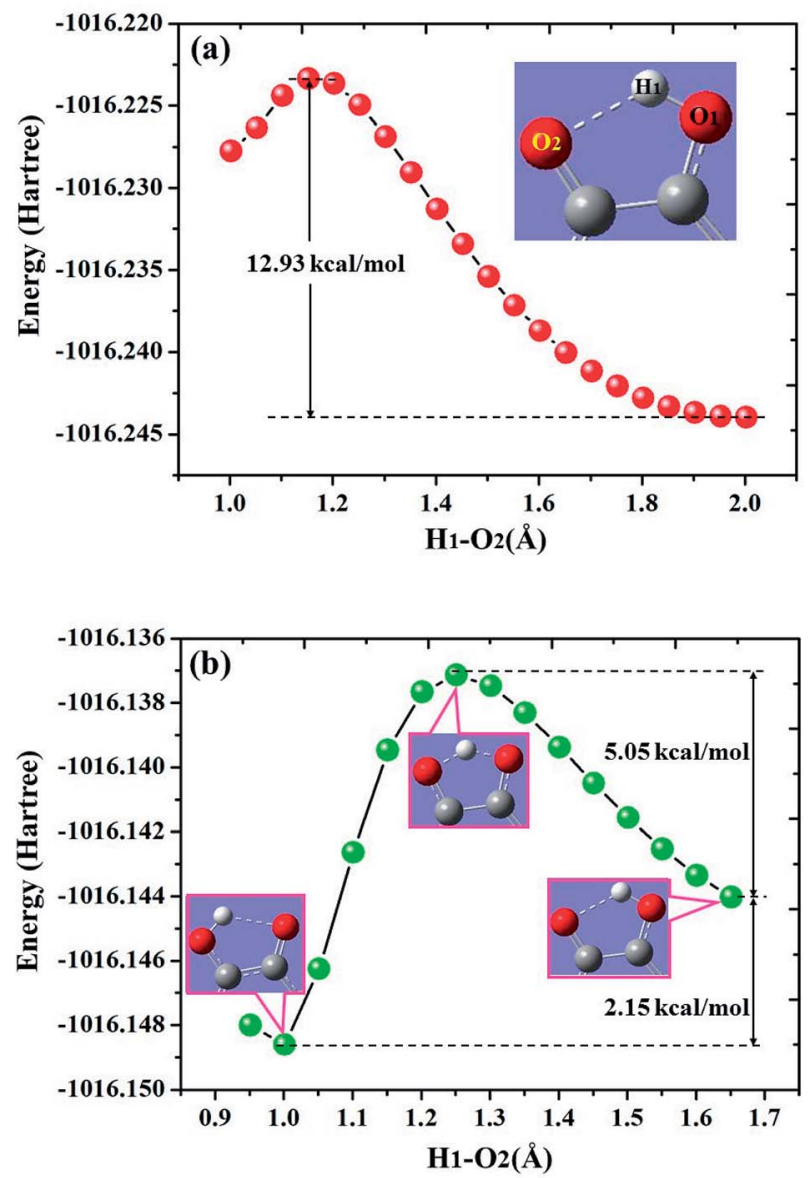

Fig. 7 Calculated potential energy curves of both $S_{0}(a)$ and $S_{1}$ (b) states for 3HFN in dichloromethane along with the $\mathrm{H}_{1}-\mathrm{O}_{2}$ bond distance at (TD)B3LYP/TZVP/IEFPCM theory level.

$\left(482.34 \mathrm{~nm}\right.$ ) of the $\mathrm{S}_{1}$-state $3 \mathbf{H F N}$ (experimental value located at about $495 \mathrm{~nm}$ (ref. 22)).

For diCN-HBO system, the $\mathrm{H}_{1}-\mathrm{N}_{1}$ bond lengths have been fixed from $1.797 \AA$ to $0.947 \AA$ in step of $-0.05 \AA$ to scan the ground state potential energy curve, as shown in Fig. 8(a). From Fig. 8(a), we can find that the potential energy is gradually increased as the distance between atoms $\mathrm{H}_{1}$ and $\mathrm{N}_{1}$ decreases from $1.797 \AA$ to $1.097 \AA$, with a high energy barrier $11.46 \mathrm{kcal} \mathrm{mol}^{-1}$. Therefore, the proton transfer cannot happen in the ground state of diCN-HBO due to the rather high potential energy barrier. Furthermore, to scan the $\mathrm{S}_{1}$-state potential energy curve, the $\mathrm{H}_{1}-\mathrm{N}_{1}$ bond lengths have been fixed from $1.653 \AA$ to $0.903 \AA$ in step of $-0.05 \AA$. Quite different from the situation in ground state, there only exist a rather small potential barrier (around $1.26 \mathrm{kcal} \mathrm{mol}^{-1}$ ) separating the $\mathrm{S}_{1}$-state diCN-HBO and the $\mathrm{S}_{1}$-PT-state diCN-HBO (shown in Fig. 2, $\mathrm{S}_{1}$-PT) configurations, as shown in Fig. 8(b). Furthermore, the transition-state geometrical structure (shown in Fig. 2, $\left.\mathrm{S}_{1}-\mathrm{TS}\right)$ corresponding to the point with the highest potential energy in Fig. 7(b) has been confirmed to only have one imaginary frequency that points to the direction of proton transfer. More important, the energy of the $\mathrm{S}_{1}$-PT-state diCN-HBO configuration is rather lower than that of the $\mathrm{S}_{1}$-state diCN-HBO 

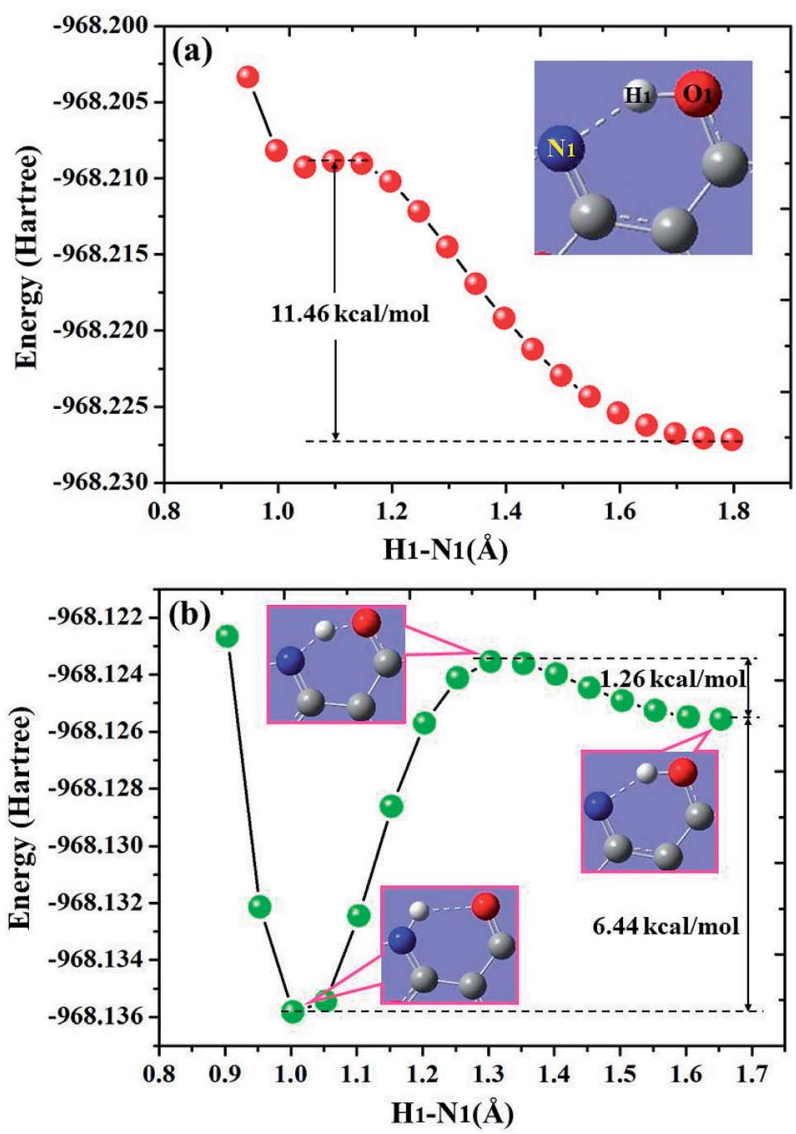

Fig. 8 Calculated potential energy curves of both $S_{0}(a)$ and $S_{1}$ (b) states for diCN-HBO in chloroform along with the $\mathrm{H}_{1}-\mathrm{N}_{1}$ bond distance at (TD)B3LYP/TZVP/IEFPCM theory level.

by $6.44 \mathrm{kcal} \mathrm{mol}^{-1}$. Thus, the intramolecular proton transfer from atom $\mathrm{O}_{1}$ to atom $\mathrm{N}_{1}$ of $\mathbf{d i C N}-\mathbf{H B O}$ can be easily realized in the first singlet excited state. After the formation of $\mathrm{S}_{1}$-PT-state diCN-HBO, the radiation fluorescent process occurs with emission peak $729.85 \mathrm{~nm}$ (experimental value located at about $650 \mathrm{~nm}$ (ref. 23)) back to ground state, which is significantly redshifted by about $250 \mathrm{~nm}$ from that $(480.7 \mathrm{~nm})$ of the $\mathrm{S}_{1}$-state diCN-HBO (experimental value located at about $435 \mathrm{~nm}$ (ref. 23)).

\section{Conclusion}

In summary, we have theoretically studied the ESIPCCT process for both 3HFN and diCN-HBO molecules. By carrying out the functional test and comparing with previous experimental data, we confirm that the theoretical level (TDDFT/B3LYP/TZVP/ IEFPCM) is more suitable for studying these two molecules. Our calculated results sufficiently confirm that intramolecular hydrogen bonds $\mathrm{O}_{1}-\mathrm{H}_{1} \cdots \mathrm{O}_{2}$ and $\mathrm{O}_{1}-\mathrm{H}_{1} \cdots \mathrm{N}_{1}$ are formed in the $\mathrm{S}_{0}$ state of $\mathbf{3 H F N}$ and diCN-HBO molecules. Analyses of hydrogen bond lengths and bond angles indicate that the intramolecular hydrogen bonds formed within 3HFN and diCNHBO molecules in ground state should be strengthened in the $\mathrm{S}_{1}$ state, which is consistent with the results obtained based on infrared spectra shifts, molecular orbitals and charge density differences maps. The significant strengthening of intramolecular hydrogen bonds $\mathrm{O}_{1}-\mathrm{H}_{1} \cdots \mathrm{O}_{2}$ and $\mathrm{O}_{1}-\mathrm{H}_{1} \cdots \mathrm{N}_{1}$ upon photoexcitation should facilitate the ESIPCCT process of the two title molecules. To obtain the detailed excited-state proton transfer mechanism, we have scanned the potential energy curves at $\mathrm{S}_{0}$ and $\mathrm{S}_{1}$ states for both 3 HFN and diCN-HBO, which show the overall perspective of the ESIPCCT dynamics and provides a clear mechanism for previous experiment.

\section{Conflicts of interest}

There are no conflicts to declare.

\section{Acknowledgements}

This work was supported by the Key Scientific Research Project of Colleges and Universities of Henan Province of China (grant no. 18A140023 and 6B140002), the Aid Project for the Mainstay Young Teachers in Henan Provincial Institutions of Higher Education of China (2014GGJS-283) and Science and Technology Research Project of Henan Province (172102210391).

\section{References}

1 T. Elsasser and H. J. Bakker, Ultrafast hydrogen bonding dynamics and proton transfer processes in the condensed phase, Kluwer Academic Publishers, Dordrecht, Boston, 2002.

2 M. H. V. Huynh and T. J. Meyer, Chem. Rev., 2007, 107, 5004.

3 S. Hammes-Schiffer, Acc. Chem. Res., 2009, 42, 1881.

4 C. J. Gagliardi, B. C. Westlake, C. A. Kent, J. J. Paul, J. M. Papanikolas and T. J. Meyer, Coord. Chem. Rev., 2010, 254, 2459.

5 S. Hammes-Schiffer, Chem. Rev., 2010, 110, 6937.

6 S. Hammes-Schiffer and A. A. Stuchebrukhov, Chem. Rev., 2010, 110, 6939.

7 G. J. Zhao and K. L. Han, Acc. Chem. Res., 2012, 45, 404.

8 J. Zhao, S. Ji, Y. Chen, H. Guo and P. Yang, Phys. Chem. Chem. Phys., 2012, 14, 8803.

9 P. T. Chou, M. L. Martinez, W. C. Cooper, D. Mcmorrow, S. T. Collins and M. Kasha, J. Phys. Chem., 1992, 96, 5203.

10 P. T. Chou, C. Y. Wei, C. P. Chang and M. S. Kuo, J. Phys. Chem., 1995, 99, 11994.

11 P. T. Chou, W. S. Yu, Y. C. Chen, C. Y. Wei and S. S. Martinez, J. Am. Chem. Soc., 1998, 120, 12927.

12 P. T. Chou, G. R. Wu, C. Y. Wei, M. Y. Shiao and Y. I. Liu, J. Phys. Chem. A, 2000, 104, 8863.

13 P. T. Chou, J. H. Liao, C. Y. Wei, C. Y. Yang, W. S. Yu and Y. H. Chou, J. Am. Chem. Soc., 2000, 122, 986.

14 P. T. Chou, W. S. Yu, C. Y. Wei, Y. M. Cheng and C. Y. Yang, J. Am. Chem. Soc., 2001, 123, 3599.

15 D. P. Yang, M. Jia, J. Y. Wu and X. Y. Song, Sci. Rep., 2017, 7, 11728.

16 J. F. Zhao, J. S. Chen, Y. L. Cui, J. Wang, L. X. Xia, Y. M. Dai, P. Song and F. C. Ma, Phys. Chem. Chem. Phys., 2015, 17, 1142. 
17 D. P. Yang, M. Jia, J. Y. Wu and X. Y. Song, J. Mol. Liq., 2017, 244, 141.

18 J. F. Zhao, H. B. Yao, J. Y. Liu and M. R. Hoffmann, J. Phys. Chem. A, 2015, 119, 681.

19 D. P. Yang, J. F. Zhao, G. Yang, N. H. Song, R. Zheng and Y. S. Wang, Org. Chem. Front., 2017, 4, 1935.

20 J. F. Zhao, J. S. Chen, J. Y. Liu and M. R. Hoffmann, Phys. Chem. Chem. Phys., 2015, 17, 11990.

21 D. P. Yang, J. F. Zhao, G. Yang, N. H. Song, R. Zheng and Y. S. Wang, J. Mol. Liq., 2017, 241, 1003.

22 P. T. Chou, S. C. Pu, Y. M. Cheng, W. S. Yu, Y. C. Yu, F. T. Hung and W. P. Hu, J. Phys. Chem. A, 2005, 109, 3777.

23 C. C. Hsieh, Y. M. Cheng, C. J. Hsu, K. Y. Chen and P. T. Chou, J. Phys. Chem. A, 2008, 112, 8323.

24 A. P. Demchenko, K. C. Tang and P. T. Chou, Chem. Soc. Rev., 2013, 42, 1379.

25 G. J. Zhao and K. L. Han, ChemPhysChem, 2008, 9, 1842.

26 G. J. Zhao and K. L. Han, J. Phys. Chem. A, 2009, 113, 14329.

27 G. J. Zhao, B. H. Northrop, K. L. Han and P. J. Stang, J. Phys. Chem. A, 2010, 114, 9007.

28 P. W. Zhou and K. L. Han, Acc. Chem. Res., 2018, 51, 1681.

29 N. Qiao, N. N. Wei, J. N. Zhang and C. Hao, New J. Chem., 2018, 42, 11804.

30 S. P. Roche, R. Cencic, J. Pelletier and J. A. Porco Jr., Angew. Chem., 2010, 122, 6683.

31 M. Jadhao, O. R. Meitei, R. Joshi, H. Kumar, C. Das and S. K. Ghosh, J. Photochem. Photobiol., A, 2016, 326, 41.

32 H. Yin, H. Li, G. M Xia, C. Y. Ruan, Y. Shi, H. M. Wang, M. X. Jin and D. J. Ding, Sci. Rep., 2016, 6, 19774.

33 P. Majumdar and J. Z. Zhao, J. Phys. Chem. B, 2015, 119, 2384. 34 C. Ma, Y. G. Yang, C. Z. Li and Y. F. Liu, J. Phys. Chem. A, 2015, 119, 12686.

35 Y. H. Liu, S. C. Lan, C. Y. Zhu and S. H. Lin, J. Phys. Chem. A, 2015, 119, 6269.

36 D. Wu, W. W. Guo, X. Y. Liu and G. L. Cui, ChemPhysChem, 2016, 17, 2340.

37 C. T. Lee, W. T. Yang and R. G. Parr, Phys. Rev. B: Condens. Matter Mater. Phys., 1988, 37, 785.

38 B. Miehlich, A. Savin, H. Stoll and H. Preuss, Chem. Phys. Lett., 1989, 157, 200.

39 W. Kolth, A. D. Becke and R. G. Parr, J. Phys. Chem., 1996, 100, 12974.

40 S. H. Vosko, L. Wilk and M. Nusair, Can. J. Phys., 1980, 58, 1200. 41 O. Treutler and R. Ahlrichs, J. Chem. Phys., 1995, 102, 346.
42 F. Furche and R. Ahlrichs, J. Chem. Phys., 2002, 117, 7433.

43 M. J. Frisch, G. W. Trucks, H. B. Schlegel, G. E. Scuseria, M. A. Robb, J. R. Cheeseman, G. Scalmani, V. Barone, B. Mennucci, G. A. Petersson, H. Nakatsuji, M. Caricato, X. Li, H. P. Hratchian, A. F. Izmaylov, J. Bloino, G. Zheng, J. L. Sonnenberg, M. Hada, M. Ehara, K. Toyota, R. Fukuda, J. Hasegawa, M. Ishida, T. Nakajima, Y. Honda, O. Kitao, H. Nakai, T. Vreven, J. A. Montgomery Jr, J. E. Peralta, F. Ogliaro, M. Bearpark, J. J. Heyd, E. Brothers, K. N. Kudin, V. N. Staroverov, T. Keith, R. Kobayashi, J. Normand, K. Raghavachari, A. Rendell, J. C. Burant, S. S. Iyengar, J. Tomasi, M. Cossi, N. Rega, J. M. Millam, M. Klene, J. E. Knox, J. B. Cross, V. Bakken, C. Adamo, J. Jaramillo, R. Gomperts, R. E. Stratmann, O. Yazyev, A. J. Austin, R. Cammi, C. Pomelli, J. W. Ochterski, R. L. Martin, K. Morokuma, V. G. Zakrzewski, G. A. Voth, P. Salvador, J. J. Dannenberg, S. Dapprich, A. D. Daniels, O. Farkas, J. B. Foresman, J. V. Ortiz, J. Cioslowski and D. J. Fox, Gaussian 09, Revision C.01, Gaussian, Inc., Wallingford CT, 2010.

44 B. Mennucci, E. Cances and J. Tomasi, J. Phys. Chem. B, 1997, 101, 10506.

45 E. Cances, B. Mennucci and J. Tomasi, J. Chem. Phys., 1997, 107, 3032.

46 R. Cammi and J. Tomasi, J. Comput. Chem., 1995, 16, 1449. 47 M. J. Frisch, G. W. Trucks, H. B. Schlegel, G. E. Scuseria, M. A. Robb, J. R. Cheeseman, G. Scalmani, V. Barone, G. A. Petersson, H. Nakatsuji, X. Li, M. Caricato, A. V. Marenich, J. Bloino, B. G. Janesko, R. Gomperts, B. Mennucci, H. P. Hratchian, J. V. Ortiz, A. F. Izmaylov, J. L. Sonnenberg, D. Williams-Young, F. Ding, F. Lipparini, F. Egidi, J. Goings, B. Peng, A. Petrone, T. Henderson, D. Ranasinghe, V. G. Zakrzewski, J. Gao, N. Rega, G. Zheng, W. Liang, M. Hada, M. Ehara, K. Toyota, R. Fukuda, J. Hasegawa, M. Ishida, T. Nakajima, Y. Honda, O. Kitao, H. Nakai, T. Vreven, K. Throssell, J. A. Montgomery Jr, J. E. Peralta, F. Ogliaro, M. J. Bearpark, J. J. Heyd, E. N. Brothers, K. N. Kudin, V. N. Staroverov, T. A. Keith, R. Kobayashi, J. Normand, K. Raghavachari, A. P. Rendell, J. C. Burant, S. S. Iyengar, J. Tomasi, M. Cossi, J. M. Millam, M. Klene, C. Adamo, R. Cammi, J. W. Ochterski, R. L. Martin, K. Morokuma, O. Farkas, J. B. Foresman and D. J. Fox, Gaussian 16, Revision A.03, Gaussian, Inc., Wallingford CT, 2016. 